\title{
Mini Review of the Relationship between Social Support and Subjective Well-Being among Older Adults in China
}

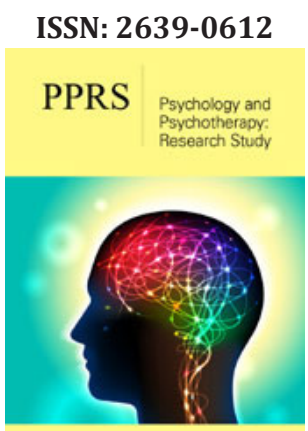

*Corresponding author: Xupeng Mao, Department of Social Work, East China University of Science and Technology, China

Submission: 温January 12, 2021

Published: 留 February 01, 2021

Volume 4 - Issue 4

How to cite this article: Xupeng Mao. Mini Review of the Relationship between Social Support and Subjective Well-Being among Older Adults in China. Psychol Psychother Res Stud. 4(4). PPRS. 0005922021. DOI: 10.31031/PPRS.2021.04.000592

Copyright@Xupeng Mao, This article is distributed under the terms of the Creative Commons Attribution 4.0 International License, which permits unrestricted use and redistribution provided that the original author and source are credited.

\section{Xupeng Mao*}

Department of Social Work, East China University of Science and Technology, China

\section{Mini Review}

Subjective well-being in later life is important to individuals, their families, and society, because it dictates how we think, feel, and behave [1]. However, studies in China have found that Chinese older adult's subjective well-being is much worse compared to 20 years ago [2]. This decrease may be due to methodological differences, but it may also reflect changes in social support that China has experienced in recent years. Chinese culture (i.e., the Confucian norm of filial piety) expects adult children to be the primary providers of support for their older parents by living with them [3]. However, significant societal and economic transitions (e.g., children's migration, one-child policy) since the 1980s have weakened the traditional social support pattern of older adults [4,5]. Empirical studies conducted during the past several decades have focused on the relationship between social support and subjective wellbeing among Chinese older adults. The majority of them explored the main effect of social support on Chinese older adults' subjective well-being. They found that having a bigger social network (e.g., more friends), receiving assistance or financial aid when needed, and frequent contact with others were positively associated with Chinese older adults' subjective wellbeing in China [6-17].

Some studies using Chinese samples also examine the relationship between sources of social support and older adults' subjective well-being. Most of them focused on children's support and generally found that it was beneficial to Chinese older adults' subjective wellbeing [3,18-20]. Studies examining the relationship between support from non-child sources and subjective well-being among Chinese older adults have been relatively scant and found mixed results. For example, some studies reported a positive relationship between friendship and subjective well-being among Chinese older adults [14,21-24] whereas others found no significant relationship between friends' support and subjective well-being $[25,26]$. In addition, although the stress-buffering model [27] is one of the dominating theories regarding social support, the potential stress-buffering role of social support for Chinese older adults' subjective well-being has been largely overlooked in the literature. Very few studies using Chinese older adult samples have examined the stress-buffering effect of social support, and they found family support had a stress-buffering effect, whereas support from friends did not [13,28-30]. Overall, although many empirical studies have examined the relationship between social support and Chinese older adults' subjective well-being, some knowledge gaps need to be addressed. First, the buffering effect of social support has been far less studied in this research area. Second, support from non-child sources (e.g., spouse, neighbors, friends, or professional services) has been overlooked, a critical gap considering changes in living arrangements among Chinese older adults from living with children to living with a spouse only or alone. Studies addressing these knowledge gaps may better unveil the relationship between social support and subjective well-being among older adults in China and have great implications for both policy and practice in serving this population.

\section{Acknowledgement}

This study was sponsored by "the Fundamental Research Funds for the Central Universities" and "Shanghai Pujiang Program (No. 2020PJC024)". 


\section{References}

1. Diener E, Lucas RE, Oishi S (2002) Subjective well-being: The science of happiness and life satisfaction. In: Snyder CR, Lopez SJ (Eds.), Handbook of positive psychology. Oxford University Press, New York, NY, USA, pp. 63-73.

2. Zhang L, Xu Y, Nie H, Zhang Y, Wu Y (2012) The prevalence of depressive symptoms among the older in China: A meta-analysis. Int J Geriatr Psychiatry 27(9): 900-906.

3. Cong Z, Silverstein M (2008a) Intergenerational support and depression among elders in rural China: Do daughters-in-law matter? Journal of Marriage and Family 70(3): 599-612.

4. Chen X, Silverstein M (2000) Intergenerational social support and the psychological well-being of older parents in China. Research on Aging 22(1): 43-65.

5. Silverstein M, Cong Z, Li S (2006) Intergenerational transfers and living arrangements of older people in rural China: Consequences for psychological well-being. J Gerontol B Psychol Sci Soc Sci 61: S256-S266.

6. Cao W, Li L, Zhou X, Zhou C (2015) Social capital and depression: Evidence from urban elderly in China. Aging Ment Health 19(5): 418429.

7. Chan YK, Lee RPL (2006) Network size, social support and happiness in later life: A comparative study of Beijing and Hong Kong. Journal of Happiness Studies 7: 87-112.

8. Cheng ST, Chan ACM (2006) Filial piety and psychological well-being in well older Chinese. J Gerontol B Psychol Sci Soc Sci 61(5): 262-269.

9. Chi I, Chou KL (2001) Social support and depression among elderly Chinese people in Hong Kong. Int J Aging Hum Dev 52(3): 231-252.

10. Chou KL, Chi I (1999) Determinants of life satisfaction in Hong Kong Chinese elderly: A longitudinal study. Aging \& Mental Health 3(4): 328335.

11. Cong L, Dou P, Chen D, Cai L (2015) Depression and associated factors in the elderly cadres in Fuzhou, China: A community-based study. International Journal of Gerontology 9(1): 29-33.

12. Deng J, Hu J, Wu W, Dong B, Wu H (2010) Subjective well-being, social support, and age-related functioning among the very old in China. Int J Geriatr Psychiatry 25(7): 697-703.

13. Leung KK, Chen CY, Lue BH, Hsu ST (2007) Social support and family functioning on psychological symptoms in elderly Chinese. Arch Gerontol Geriatr 44(2): 203-213.

14. Poulin JE, Rong D (2012) Informal support and psychological well-being of older Chinese community residents. China Journal of Social Work 5(2): 149-161.

15. Woo J, Ho SC, Lau J, Yuen YK, Chiu H, et al. (1994) The prevalence of depressive symptoms and predisposing factors in an elderly Chinese population. Acta Psychiatr Scand 89(1): 8-13.
16. Wu ZQ Sun L, Sun YH, Zhang XJ, Tao FB, et al. (2010) Correlation between loneliness and social relationship among empty nest elderly in Anhui rural area, China. Aging Ment Health 14(1): 108-112.

17. Zhang B, Li J (2011) Gender and marital status differences in depressive symptoms among elderly adults: The roles of family support and friend support. Aging Ment Health 15(7): 844-854.

18. Cong Z, Silverstein M (2008b) Intergenerational time-for-money exchanges in rural China: Does reciprocity reduce depressive symptoms of older grandparents? Research in Human Development 5(1): 6-25.

19. Jia SM, Shi YJ, Zhou H, Fu J, Lv B (2007) A survey on anxiety and depression and the influencing factors in the elderly of 'empty nest' in a community. Journal of Nursing Science 22(14): 8-10.

20.Su D, Wu XN, Zhang YX, Li HP, Wang WL, et al. (2012) Depression and social support between China's rural and urban empty-nest elderly. Arch Gerontol Geriatr 55(3): 564-569.

21. Li H, Ji Y, Chen T (2014) The roles of different sources of social support on emotional well-being among Chinese elderly. PlOS One 9(3): e90051.

22. Poulin J, Deng R, Ingersoll TS, Witt H, Swain M (2012) Perceived family and friend support and the psychological well-being of American and Chinese elderly persons. J Cross Cult Gerontol 27(4): 305-317.

23. Sun X, Lucas H, Meng Q, Zhang Y (2011) Associations between living arrangements and health-related quality of life of urban elderly people: A study from China. Qual Life Res 20(3): 359-369.

24. Wang J, Zhao X (2012) Family functioning and social support for older patients with depression in an urban area of Shanghai, China. Arch Gerontol Geriatr 55(3): 574-579.

25. Cheng ST, Li KK, Leung EMF, Chan ACM (2011) Social exchanges and subjective well-being: Do sources of positive and negative exchanges matter? J Gerontol B Psychol Sci Soc Sci 66(6): 708-718.

26. Wang L, Tang D, Xu J, Shen J (2006) The sex difference of effect of social support on depressive symptoms of the elderly in China. Chinese Journal of Clinical Psychology 14: 70-72.

27. Cohen S, Wills TA (1985) Stress, social support, and the buffering hypothesis. Psychol Bull 98(2): 310-357.

28. Li L, Liang J, Toler A, Gu S (2005) Widowhood and depressive symptoms among older Chinese: Do gender and source of support make a difference? Social Science \& Medicine 60(3): 637-647.

29. Chou KL, Chi I (2000) Comparison between elderly Chinese living alone and those living with others. Journal of Gerontological Social Work 33(4): 51-66.

30. Diener E (1984) Subjective well-being. Psychological Bulletin 95(3): 542-575. 